\title{
Correction to: Contemporary Art and Unforgetting in Colonial Landscapes
}

\section{Correction to:}

K. McMillan, Contemporary Art and Unforgetting in Colonial Landscapes, Palgrave Macmillan Memory Studies, https://doi. org/10.1007/978-3-030-17290-9

The original version of this chapter was inadvertently published with an incorrect Artist name "Gaugin", which has now been corrected to "Gauguin" in Chapters 1 and 4. The chapter has been updated with the changes.

The updated versions of these chapters can be found at https://doi.org/10.1007/978-3-030-17290-9_1 https://doi.org/10.1007/978-3-030-17290-9_4

(C) The Author(s) 2021

K. McMillan, Contemporary Art and Unforgetting in Colonial Landscapes, Palgrave Macmillan Memory Studies, https://doi.org/10.1007/978-3-030-17290-9_9 